
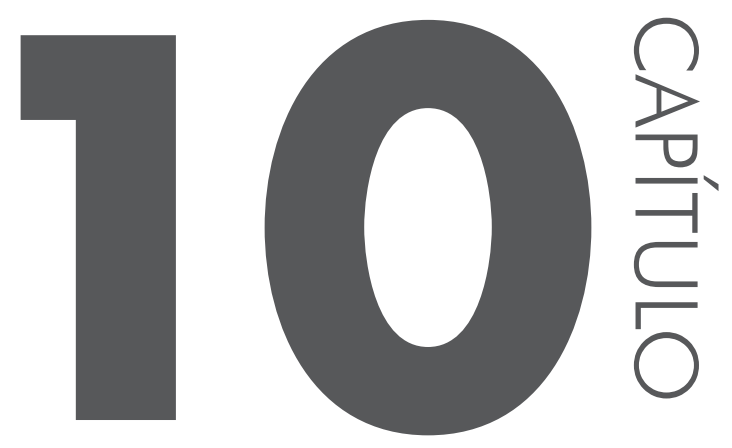

\title{
ELABORAÇÃO DE \\ SNACK DE BATATA-DOCE \\ (IPOMOEA BATATAS)
}

Viviane Ribeirete de Campos Caroline Maria Calliari

\section{INTRODUÇÃO}

Atualmente, o mercado tem sofrido algumas modificações para competitividade no mundo. Assim, os profissionais necessitam reduzir seu tempo de pausa na hora das refeições, por isso buscam alimentações mais rápidas, como fast foods, medida que pode levar a um aumento de sobrepeso da população (BEZERRA; SICHIERI, 2010). Entretanto, uma parte da população busca uma alimentação mais saudável, evitando o consumo de alimentos industrializados. O hábito de consumo de alimentos saudáveis tem como objetivo reduzir as doenças por infecção na população, e criar uma alimentação mais equilibrada e rica em nutrientes. A alimentação está vinculada à forma como o alimento é consumido e às práticas alimentares, de modo a terem um significado social (BRASIL, 2008). 
A batata-doce (Ipomoea batatas) pertence à família das Convolvulaceae, e pode ser classificada como raiz tuberosa. É originária da América Central e do Sul, e sua espécie existe há mais de dez mil anos, com base em análises de batatas secas encontradas em cavernas no Peru e em regiões ocupadas pelos Maias (EMBRAPA, 2007). Essa batata possui dois tipos de raízes, a tuberosa, correspondente à parte comercializada e que pode ser chamada de "reserva", e a raiz absorvente, que, como o nome já diz, absorve os nutrientes e a água do solo (EMBRAPA, 2007).

As culturas de mandioquinha-salsa, batata-doce, taro e inhame são comercializadas in natura no Brasil, e apresentam potencial significativo de crescimento, necessitando de pesquisas que apontem alternativas de comercialização para maiores investimentos no setor produtivo e na inserção das tuberosas como matérias-primas industriais (ROGÉRIO; LEONEL, 2004).

A região que mais se destaca na produção de batata-doce no Brasil são as regiões do Rio Grande do Sul e sul de Minas Gerais (G1, 2013). A vida útil da batata-doce é de aproximadamente algumas semanas, por isso é preciso consumi-las em um curto período de tempo (PERES, 2012). Sendo muito perecível, torna-se necessário aumentar sua vida útil, aplicando-se a técnica de desidratação ou o emprego de outros métodos de conservação (FONTES et al., 2012).

A batata-doce apresenta 90\%de carboidratos, compostos por açúcares, em sua massa seca. Os carboidratos aumentam o valor calórico, sendo o amido a principal fonte deste (BOUWKAMP, 1985). Segundo a legislação (BRASIL, 2003), é recomendada a ingestão de $300 \mathrm{~g} /$ dia de carboidratos e, de acordo com Carvalho (2003), é recomendada uma ingestão entre 5 g e 10 g por quilograma de peso corporal/dia, dependendo do tipo e duração do exercício físico praticado.

Com base em estudos, durante a prática de exercícios de alta intensidade, a maioria da demanda energética é suprida pela energia da degradação dos carboidratos, os quais são armazenados em forma de glicogênio (MAUGHAN et al., 2000). Quanto maior for a intensidade dos exercícios, maior será a participação dos carboidratos como fornecedores de energia (CARVALHO, 2003). A manutenção da dieta com uma alimentação rica em carboidratos é fundamental para a reposição muscular e hepática, pois vários fatores afetarão a restauração do glicogênio (COELHO et al., 2004).

Segundo Coyle (2005), as informações sobre alimentação devem ser claras e simples, tanto para atletas como para não atletas. Alimentos ricos em carboidratos e com índice glicêmico de moderado a alto são boas fontes de carboidratos para síntese de glicogênio muscular, e devem ser a primeira escolha de carboidratos nas refeições de recuperação (realizadas após a prática de atividade física intensa).

Tendo em vista esse contexto, o presente trabalho visou à elaboração de um snack de batata-doce assado em forno micro-ondas, com a aplicação de um teste 
sensorial para verificar a aceitação do produto e a intenção de compra, seguida de análises físico-químicas para definir a composição proximal da batata-doce in natura e do snack.

\section{BATATA-DOCE}

Raízes tuberosas são vegetais cujos nutrientes se acumulam dentro da raiz, embaixo da terra, e o caule permanece acima da superfície. A raiz serve como reserva de carboidratos, vitaminas, minerais, fibras, entre vários outros nutrientes que são fonte de energia alimentar, sendo benéficos para o consumo humano. Exemplos de raízes tuberosas são: batata-doce, cenoura, beterraba, mandioca e nabo (LEONEL; CEREDA, 2002).

A batata-doce (Ipomoea batata) pertence à família das Convolvuláceas, nativa da América Central; é uma planta rasteira classificada como raiz tuberosa e não precisa de muitos cuidados para cultivo, pois apresenta resistência a pragas e a degradações. Pode ser cultivada em diversos locais e climas, como tropical, temperado e até desértico; sua maior produção fica na Ásia, chegando a 90\% da produção mundial. No Brasil, existem quatro tipos de batata-doce, classificadas, de acordo com a cor da polpa, em batata-branca, batata-amarela, batata-roxa e batata-doce-avermelhada. É considerado um alimento com grande fonte energética e nutricional pelo seu baixo índice glicêmico, diminuindo a sensação de fome e aumentando a saciedade, auxiliando, assim, no controle do peso. É um alimento destinado a humanos e animais, e tem importância na produção industrial de farinha, amido e álcool (FONTES et al., 2012). Segundo Souza e Sandri (1990), os tubérculos podem ser consumidos na forma fresca, in natura, cozida, fervida e também processada, em forma de salgadinhos com alto teor de amido.

De acordo com Fontes et al. (2012), o Brasil produz cerca de 533.000 toneladas de batata-doce por ano, tornando-se o principal produtor do continente latino-americano. Por ser um alimento muito perecível, é necessário aumentar sua vida útil através de processos como a desidratação, que promove, nas propriedades macroscópicas da batata-doce, mudança de cor, aparência e textura do produto final, além de diminuir a massa do alimento, garantindo economia e praticidade para armazenamento.

A batata-doce é rica em sacarose e carboidratos, tendo pequena quantidade de glicose e frutose. Atualmente, a batata-doce está na dieta das pessoas e, principalmente, dos praticantes de musculação pelo seu baixo índice glicêmico, que irá refletir no impacto promovido pelo carboidrato nos níveis sanguíneos de glicose. $\mathrm{O}$ índice glicêmico da batata-doce em relação à glicose é em torno de 44, sendo considerado mais baixo em comparação com o pão branco, que chega a 71 , por isso se torna ideal para ser consumida como fonte de carboidrato durante o dia, e entre uma e duas horas antes de treinamentos utilizando pesos (PERES, 2012). 
Segundo Peres (2012), além de a batata-doce ter um baixo índice glicêmico, liberando menor quantidade de açúcar no sangue, causa maior saciedade e auxilia na perda de peso, possui alta concentração de vitamina A (predominante na amarela e roxa), vitaminas do complexo B e sais minerais, como ferro, cálcio, fósforo, potássio e uma pequena quantidade de vitamina $\mathrm{C}$, podendo-se utilizar também suas folhas na preparação de verduras. Muito confundida com a batata inglesa, por terem valores nutricionais semelhantes, se diferem em alguns requisitos, como maior índice glicêmico da batata inglesa e altos teores de ferro, cálcio e vitamina A da batata-doce, que também possui mais fibras. A batata-doce fornece, em média, para cada 100 gramas: 116 calorias, 1,16 gramas de proteínas, 30,10 gramas de carboidratos e 0,32 gramas de lipídios.

Esse tubérculo pode ser consumido cozido, assado ou na forma de doce. Pode ser chamado de alimento de conveniência, tendo forte crescimento no mundo atual, pois supre as necessidades daqueles que não têm tempo para fazer uma refeição adequada. É preciso que haja mais pesquisas sobre esse alimento para que se possam produzir salgadinhos fritos ou assados de alta qualidade (ROGÉRIO; LEONEL, 2004).

A batata-doce é uma fonte alternativa de carboidratos, possui grande reserva de energia, betacaroteno, vitamina $\mathrm{C}$, niacina, riboflavina, tiamina e vários minerais. Algumas variedades de batata apresentam quantidades de vitamina A superiores às do arroz e são boas fontes de fósforo, cálcio e potássio (FRANCO, 1996).

Entre outros cultivos alimentares, o cultivo de batata-doce é de colheita fácil e muito produtiva, tendo menos problemas no campo, com alto rendimento em curto período de tempo, adaptável a vários climas. Atualmente, o cultivo de batata-doce apresenta baixo valor econômico, mas com significativa importância social, pois é um alimento versátil, utilizado para lanches, alimentação básica, chips, snacks e, muitas vezes, substitui o arroz (SOUZA; SANDRI, 1990).

$\mathrm{Na}$ área urbana, vários lanches, snacks e sobremesas são feitos a partir da batata-doce, e esse tubérculo está se tornando cada vez mais comum (ALIMENTOS E BEBIDAS, 2013). Como uma fonte de alimentação secundária, a batata-doce tem alto rendimento e é muito versátil em seus usos, sendo rica em carboidratos e com alto valor nutricional, considerada como futuro cultivar alimentar, que pode ser utilizado para recompensar a escassez de outros alimentos (ALIMENTOS E BEBIDAS, 2013).

\subsection{Carboidratos}

Os carboidratos são os "combustíveis da vida", pois armazenam energia nos seres vivos, na forma de amido e glicogênio, que são liberados para as reações metabólicas quando degradados, em especial com a glicose. Podem ser doadores de carbono para a síntese de outros constituintes das células (POMIN; MOURÃO, 2006). 
A utilização de estratégias nutricionais envolvendo uma alimentação rica em carboidratos antes da prática de exercícios físicos aumenta as reservas de glicogênio, tanto muscular quanto hepático. Já a ingestão de carboidratos durante o esforço físico ajuda na manutenção da glicemia sanguínea e na oxidação desses substratos. Após o esforço, a ingestão de carboidratos visa repor os estoques consumidos e garante o padrão anabólico (CYRINO; ZUCAS, 1999).

$\mathrm{O}$ índice glicêmico é um mecanismo criado para avaliar o efeito dos carboidratos nos níveis de glicose sanguínea, já que o organismo digere e absorve diferentes carboidratos em velocidades variáveis. O índice glicêmico de um carboidrato é proporcional ao aumento da glicemia no sangue. A partir dessa informação, é possível elaborar um plano nutricional apropriado em relação à suplementação de carboidratos para o indivíduo, de acordo com a sua atividade física, norteando a seleção das fontes de carboidratos da dieta (SAPATA; FAYH; OLIVEIRA, 2006).

\subsection{Snacks}

Alimentos de conveniência ou fast foods englobam os snacks e apresentam elevada demanda no mundo todo, frente aos hábitos rotineiros da população que dispõe de cada vez menos tempo para as refeições (ZELAYA, 2000).

Esses salgadinhos incluem uma variedade de produtos e formas e, devido à praticidade, observa-se aumento significativo de seu consumo entre as refeições (CEREDA; VILPOUX; FRANCO, 2003). No Brasil, novos salgadinhos estão ganhando importância e verifica-se seu crescimento no mercado, com uma infinidade de possibilidades e inovações a serem exploradas (LIMBERGER, 2006).

Os snacks apresentam uma variedade de formas, podendo ser processados a partir de ingredientes frescos ou não, sendo muitas vezes consumidos em quantidades menores que uma refeição regular. Eles são concebidos para serem práticos, portáteis e satisfatórios, sendo menos perecíveis e mais duráveis (GOMES, 2009).

No mercado, atualmente encontra-se grande variedade de snacks doces com pedaços de frutas desidratadas, que apresentam nutrientes concentrados devido ao processo de desidratação, podendo-se considerar que todos os nutrientes permanecem no produto final, exceto a vitamina $\mathrm{C}$ e a água, enquanto a concentração de fibras e carboidratos é potencializada (PRESEA ALIMENTOS, 2014). São considerados uma opção de produtos saudáveis, pois não sofrem adição de compostos químicos, apenas passam pelo processo de desidratação (GOMES, 2009). Recomenda-se que sejam colocados na área light e diet em supermercados, por terem como público-alvo indivíduos preocupados com a saúde e por possuírem alta concentração de nutrientes (GOMES, 2009). 
Outra classe de snack são os assados e extrusados, geralmente feitos com milho, que passam por um cozimento ou pela extrusora, e seus grãos são moídos para formar uma massa uniforme que passa por um esticamento e é cortada nas formas desejadas (GOMES, 2009). Depois de cortada, a massa é assada em forno industrial, podendo ser frita ou não ao final, para ficar mais crocante, podendo passar ainda, no último estágio de produção, por um aromatizador para receber os temperos em pó antes de ser embalada (GOMES, 2009).

\subsection{Micro-ondas}

As micro-ondas são uma invenção utilizada na Segunda Guerra Mundial como radar, com o objetivo de detectar frotas inimigas invasoras, que refletiam em superfícies metálicas (INMETRO, 2000). Essas micro-ondas são um tipo de energia radiante, como ondas de rádio, infravermelho e eletricidade, possuindo radiação eletromagnética; através do seu efeito térmico, é possível cozinhar os alimentos (INMETRO, 2000).

Segundo o INMETRO (2000), as micro-ondas têm uma radiação não ionizante, por isso seus efeitos são térmicos, não alterando a estrutura molecular do item irradiado. O cozimento se dá por vibração molecular: as micro-ondas penetram superficialmente nos alimentos (de dois a quatro centímetros), vibrando as moléculas de água, gordura e açúcar, e acontece a transferência de calor por condução - a vibração das moléculas e o choque entre elas resulta na vibração de todas as moléculas, cozinhando todo o alimento. A radiação não ionizante causa migração de íons e rotação de dipolos, porém não promove alteração nas estruturas moleculares (ROSINI; NASCENTES; NÓBREGA, 2004).

A aplicação de micro-ondas no processamento de alimentos, de um modo geral, tem crescido devido ao fato de esta energia ser considerada mais eficiente que a do processo de aquecimento convencional (ALTON, 1998). Algumas vantagens relacionadas à sua utilização são a economia de espaço e a eficiência da energia, uma vez que a maior parte da energia eletromagnética é convertida em calor (MERMELSTEIN, 1997).

O forno de micro-ondas é utilizado para várias finalidades, como secagem da amostra, sínteses, extração de compostos orgânicos e mineralização de amostras orgânicas e inorgânicas (ROSINI; NASCENTES; NÓBREGA, 2004).

\subsection{Sal rosa do Himalaia}

Entre os nutrientes minerais, o sal é um dos mais importantes para o corpo humano, porém seu consumo em excesso pode causar danos à saúde. É tradicional sua utilização para tempero de alimentos, sendo usado em grandes quantida- 
des. Porém, ao ser ingerido em grande quantidade, o organismo absorve a água pelo cloreto, fazendo com que o corpo aumente a pressão arterial para equilibrar a falta de água (LANE, 2008).

Com o aumento da pressão, o corpo diminui o fluxo sanguíneo numa tentativa de retornar à pressão para o normal. Assim, com a alteração da pressão, o coração começa a trabalhar com sobrecarga, deixando seu tecido mais espesso, acarretando riscos como hipertensão, arritmia, insuficiência renal e até infarto (LANE, 2008).

A textura e a cor do sal dependem da sua origem, e a composição dos minerais é o principal fator que os diferencia, pois o teor de cloreto de sódio é elevado em todos os sais. Segundo Caleffi (2012), o sal rosa do Himalaia pode ser considerado um sal orgânico, sua cor rosa é devida aos índices elevados de minerais, colhido nos depósitos milenares quando o mar chegava às montanhas do Himalaia.

O sal rosa do Himalaia difere dos outros sais industrializados por estar na forma de cristais, recolhidos manualmente, sem sofrer nenhum tipo de refinamento. É fonte de mais de setenta oligo-elementos que estimulam os mecanismos de hidratação, evitando a diferenciação celular e favorecendo a produção de fatores naturais de hidratação da pele (CALEFFI, 2012). O produto é uma fonte de nutrientes essenciais ao organismo, como magnésio, cálcio, potássio e ferro, entre outros. De acordo com vários pesquisadores, além de fornecer minerais essenciais, o sal rosa contribui para o equilíbrio dos eletrólitos do corpo, melhorando a capacidade de absorção de nutrientes, regulando o $\mathrm{pH}$ do organismo, normalizando a pressão sanguínea, melhorando a circulação e a condutividade, benefícios que são resultado do processamento mínimo para retirar impurezas, mantendo os nutrientes (LANE, 2008).

O sal de cozinha passa por vários processos de industrialização, retirando-se normalmente o que este possuiria de nutritivo. Para praticantes de exercícios, o organismo necessita de mais sal devido às perdas pela transpiração. Entretanto, o sal tradicional não fornece os nutrientes que repõem os minerais gastos nas atividades, enquanto o consumo do sal rosa do Himalaia supre as necessidades do organismo de forma natural e mais saudável (ADITIVOS E INGREDIENTES, 2014).

\subsection{Chimichurri}

As especiarias tornam os alimentos mais atrativos ao consumidor por suas características e por apresentarem benefícios à saúde (PEREIRA et al., 2006). Podem estimular o apetite e conferir aroma antes e durante o cozimento dos alimentos, sendo responsáveis pelos sabores picantes e utilizadas para temperar azeites (GERMANO, 2008). 
Os sabores são compostos de álcoois, aldeídos, ésteres, fenóis e ácidos orgânicos, cujas concentrações podem variar de $0,5 \%$ a $1 \%$ no produto final (BEDIN; GUTKOSKI; WIEST, 1999). Desde a antiguidade, o homem busca inovar nos gostos e sabores dos alimentos (ABREU, 2006), mas, com a mudança de valores dos consumidores, as especiarias tiveram um avanço na produção industrial alimentícia por conferir sabores e odores agradáveis, e por possuírem óleos essenciais com propriedades antioxidantes, antitoxigênicas, entre outras (KRUGER, 2006).

As especiarias devem ser obtidas de maneira adequada, desde a colheita no estado certo de maturação, até chegar ao consumidor, passando por vários tratamentos, como lavagens, descascamento, cura e secagem (ALMEIDA, 2006). Os consumidores buscam cada vez mais alimentos de boa qualidade, sem conservantes e com o mínimo de aditivos químicos, mas com uma vida útil longa (GOULD, 1995).

O chimichurri é um tempero originário da Argentina, podendo ser sólido ou líquido, e consiste em uma mistura de ingredientes como orégano, salsinha, cebolinha, alho, pimenta e páprica (TRONCOSO; GUIJA; QUIROZ, 2003).

Segundo Troncoso, Guija e Quiroz (2003), estudos indicam que o chimichurri foi inventado no século XIX, nos acampamentos militares argentinos, pelo irlandês Jimmy McCarry. O nome dessa especiaria se baseia no modo como os argentinos pronunciavam o nome de seu inventor, de forma que o tempero ficou conhecido como "chimichurri". Alguns gastrônomos afirmam que o chimichurri é uma derivação do pesto genovês.

\section{MATERIAIS E MÉTODOS}

Os materiais em estudo - batata-doce roxa e chimichurri - foram obtidos em supermercados de Londrina em maio de 2014. O sal rosa do Himalaia foi obtido em loja de produtos naturais. Foram pesados cerca de $2 \mathrm{~kg}$ de batata-doce, os quais foram divididos entre a elaboração do snack e as análises físico-químicas. Os snacks foram armazenados em temperatura ambiente e as amostras in natura foram armazenadas sob refrigeração a $10{ }^{\circ} \mathrm{C}$.

Primeiramente, foi realizado o preparo da matéria-prima utilizada para a elaboração dos snacks que, em seguida, foram submetidas à análise sensorial, juntamente com a análise das características físico-químicas desses produtos e da matéria-prima, ambos em triplicata, para determinar o teor de umidade, cinzas, proteínas, lipídeos e carboidratos, segundo a metodologia do Instituto Adolfo Lutz (2008). As análises físico-químicas foram realizadas no Laboratório de Frutas e Vegetais e no Laboratório de Análise de Alimentos da Universidade Tecnológica Federal do Paraná - campus Londrina. 


\subsection{Elaboração do snack de batata-doce}

Na Figura 10.1, demonstram-se todas as etapas da elaboração do snack de batata-doce, a serem explanadas na sua sequência.

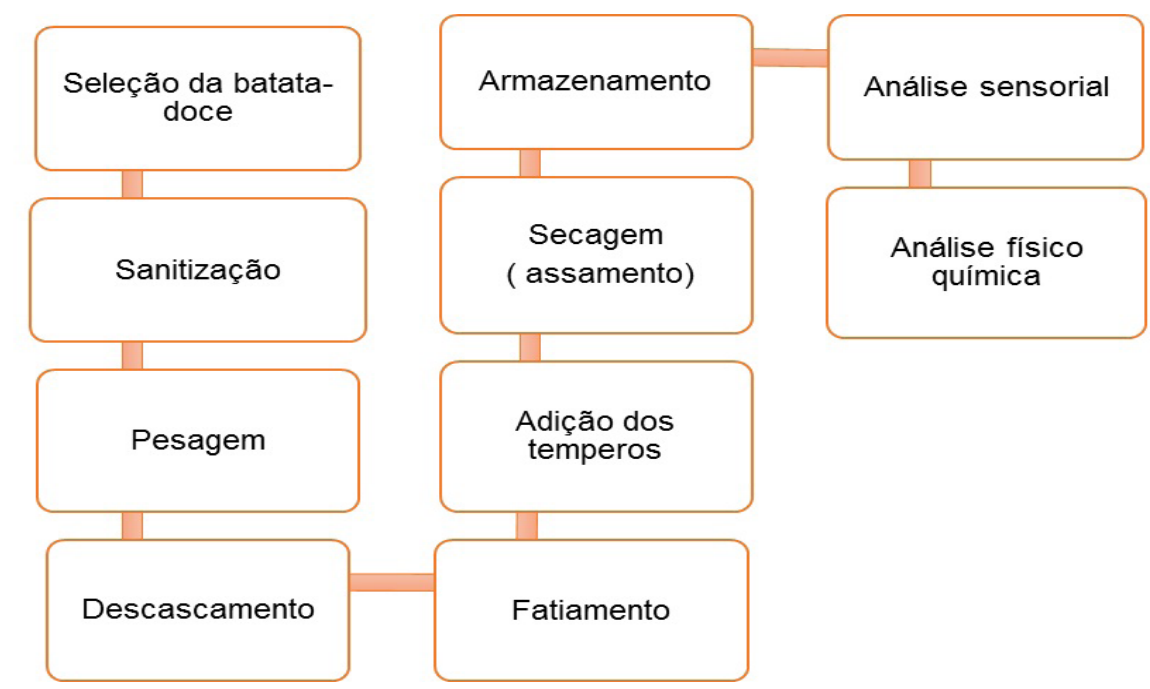

Figura 10.1 Esquema de processamento do snack de batata-doce

Os tubérculos de batata-doce foram previamente selecionados, sendo observadas características como estado de maturação, cheiro, condição da casca, tamanho, presença de ferimentos e podridões. Depois da seleção, as batatas-doces foram lavadas em água corrente para retirada de sujidades, em seguida, foram imersas em água clorada 50 ppm por quinze minutos e, após a lavagem em água corrente, foram secadas com papel toalha.

Todos os tubérculos, antes de passarem pelas operações de processamento e com exceção da operação de lavagem, foram pesados em uma balança com capacidade para $5 \mathrm{~kg}$.

As batatas foram descascadas manualmente com um descascador de tubérculos e vegetais, sendo retiradas as cascas e alguns defeitos na polpa e, em seguida foram pesadas novamente. Após o descascamento, as batatas foram fatiadas com aproximadamente $4 \mathrm{~mm}$ de espessura, já no formato de snack, para não interferir no processo de secagem, sendo, logo em seguida, imersas em uma solução aquosa de suco de limão (5:100) durante cinco minutos para evitar o escurecimento enzimático das fatias. As batatas fatiadas passaram pelo processo de adição dos temperos, onde foram formuladas duas amostras de snack: a formulação 1 contendo $5 \mathrm{~g}$ de sal rosa do Himalaia, e a formulação 2, com $11 \mathrm{~g}$ de chimichurri e 5,5 g de sal rosa para cada $1 \mathrm{~kg}$ de batata. Então, as batatas-doces fatiadas e já com 
temperos foram dispostas uniformemente em prato de vidro e foram mantidas em forno de micro-ondas, com temperatura de $150{ }^{\circ} \mathrm{C}$, durante 2,5 minutos de cada lado da amostra, totalizando 5 minutos.

Finalizados esses procedimentos, os snacks foram resfriados em temperatura ambiente, pesados e armazenados em plásticos vedados, de forma a evitar a entrada de umidade, permitindo que o produto estivesse em condições ideais para as análises sensorial e físico-químicas. A Figura 10.2 apresenta todo o procedimento de elaboração do snack de batata-doce.

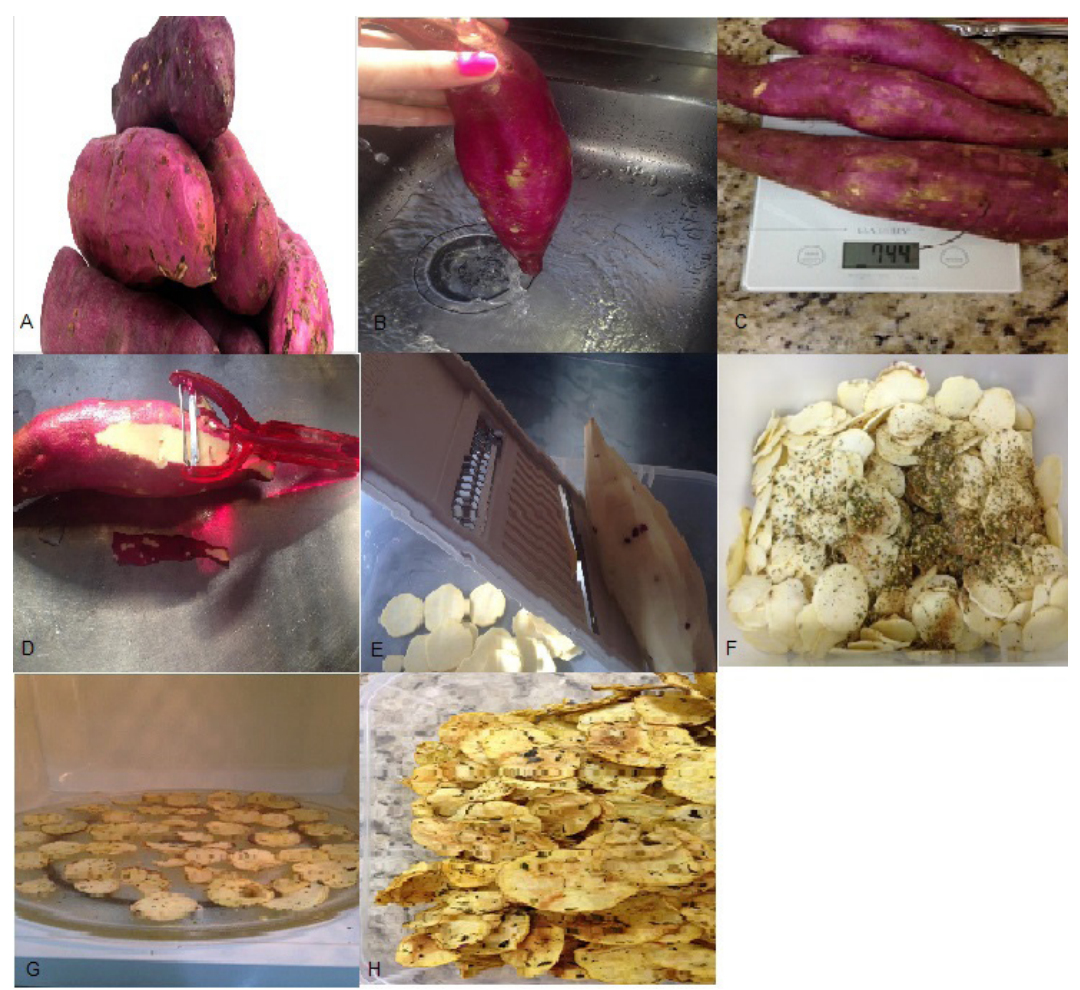

Figura 10.2 Elaboração do snack de batata-doce. A: seleção da batata-doce; B: sanitização da batata-doce; C: pesagem; D: descascamento; E: fatiamento; F: adição de tempero na batata-doce; G: batata-doce no forno micro-ondas; $\boldsymbol{H}$ : snack armazenado em saco plástico (foto tirada com o saco aberto para melhor visualização do produto final)

\subsection{Análise sensorial}

A análise sensorial foi realizada no Laboratório de Análise Sensorial da Universidade Tecnológica Federal do Paraná - campus Londrina. O teste sensorial para verificação dos snacks teve a presença de oitenta provadores. Foi realizado 
um teste de aceitação das amostras, onde uma das amostras continha apenas sal rosa como tempero, e a outra continha sal rosa e chimichurri. Utilizando-se de uma escala hedônica de dez pontos (VILLANUEVA; PETENATE; DA SILVA, 2005), cuja nota dez expressa "gostei extremamente"; cinco, "não gostei nem desgostei"; e zero, "desgostei extremamente", avaliou-se a aceitação do produto e, em seguida, a intenção de compra do mesmo pelos participantes.

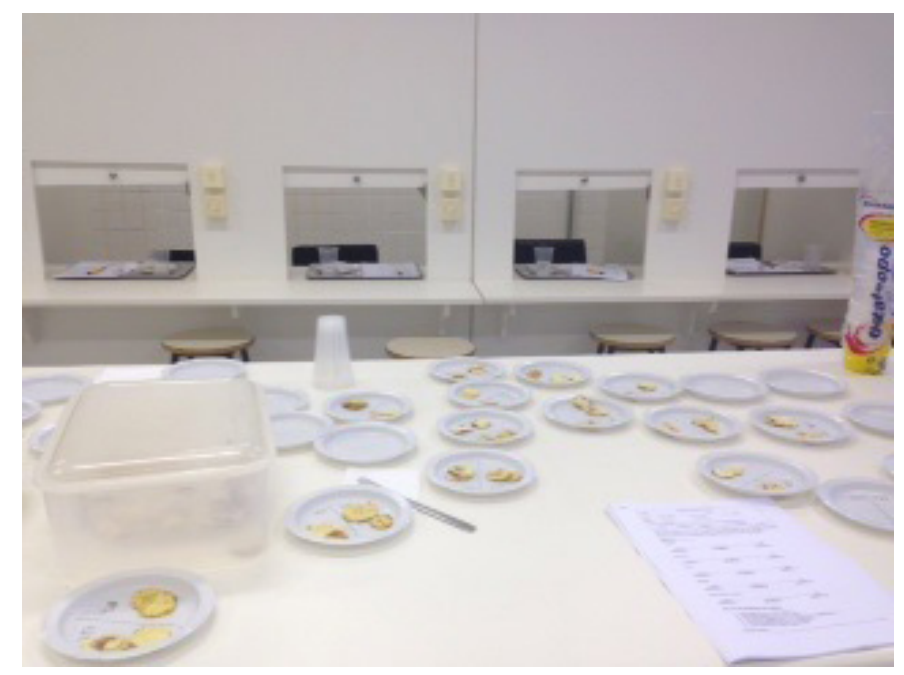

Figura 10.3 Análise sensorial das amostras

\subsection{Análises físico-químicas}

As análises físico-químicas de determinação do teor de umidade, cinzas, lipídeos, proteínas e carboidratos foram realizadas de acordo com a metodologia do Instituto Adolfo Lutz (2008), da batata-doce in natura e do snack de batata-doce com chimichurri e sal rosa, a mais aceita pelos provadores.

\subsubsection{Determinação do teor de umidade}

A umidade representa a água contida no alimento, e pode ser classificada como água livre pertencente à superfície externa do alimento, e como água liga$\mathrm{da}$, encontrada no interior do alimento. O método usado foi o aquecimento da amostra a $105{ }^{\circ} \mathrm{C}$, obtendo-se o resíduo seco. Essas análises foram realizadas no dia da produção dos snacks e da realização do teste sensorial.

De acordo com o Instituto Adolfo Lutz (2008), a determinação da umidade consiste na pesagem de aproximadamente cinco gramas da amostra em cápsula de porcelana, previamente tarada, aquecida em estufa até peso constante, resfriada em temperatura ambiente, e pesada para verificar o resíduo seco e a quantida- 
de de umidade perdida do snack em relação à amostra in natura. Para a obtenção dos resultados, é utilizada a Equação 1.

$$
(100 \mathrm{xN}) / \mathrm{P}=\text { umidade }
$$

Onde:

$\mathrm{N}$ : número de gramas de umidade (perda de massa em gramas)

P: número de gramas da amostra

Equação 1 - Expressão matemática para o cálculo do teor de umidade.

\subsubsection{Determinação do teor de cinzas}

Incineração ou cinza é o resíduo obtido por aquecimento de um produto a $550{ }^{\circ} \mathrm{C}$, sendo que alguns sais da substância inorgânica presentes na amostra podem sofrer redução ou volatilização no aquecimento (INSTITUTO ADOLFO LUTZ, 2008). Foram pesados aproximadamente cinco gramas da amostra, em cadinho previamente aquecido, e resfriado em dessecador. As amostras foram carbonizadas em bico de Bunsen, em seguida foram colocas na mufla por um período de doze horas, após o qual os cadinhos foram colocados em um dessecador e pesados na sequência. A Equação 2 foi utilizada para determinação das cinzas:

$$
(100 \mathrm{x} N) / \mathrm{P}=\text { cinzas }
$$

Onde:

$\mathrm{N}$ : número de gramas de cinzas

P: número de gramas da amostra

Equação 2 - Expressão matemática para o cálculo do teor de cinzas.

\subsubsection{Determinação do teor de lipídeos}

Os lipídeos são compostos orgânicos altamente energéticos que atuam como transportadores das vitaminas lipossolúveis, contêm ácidos graxos essenciais ao organismo, são insolúveis em água e solúveis em solventes orgânicos, como éter e acetona, entre outros (INSTITUTO ADOLFO LUTZ, 2008).

Para determinação da quantidade de lipídeos, foram pesados cinco gramas da amostra, o papel de filtro foi transferido para o aparelho extrator Soxhlet automatizado Soxtec, marca FOSS. A unidade de extração de Soxtec 8000 realiza as quatros etapas de extração de ebulição, a lavagem, a recuperação do solvente e autodesligar, é totalmente automática e funciona de acordo com o método de Randall melhorado Soxhlet. 
Foi acoplado ao extrator o copo de alumínio previamente tarado a $105{ }^{\circ} \mathrm{C}$. Adicionou-se o solvente extrator (60 $\mathrm{ml}$ de éter de petróleo), que foi mantido em aquecimento em chapa elétrica para a extração que ocorreu por aproximadamente setenta minutos. Logo após esse procedimento, os copos contendo o lipídio extraído foram retirados do aparelho extrator e colocados na estufa a $105{ }^{\circ} \mathrm{C}$ por uma hora; após a secagem, foram pesados novamente. A Equação 3, utilizada para calcular o teor de lipídeos, dá o resultado em porcentagem.

$$
\text { (100xN) / P = lipídeos\% }
$$

Onde:

N: número de gramas de lipídeos

P: número de gramas da amostra

Equação 3 - Expressão matemática para o cálculo do teor de lipídeos

\subsubsection{Determinação do teor de proteínas}

A determinação do teor de proteínas baseia-se na determinação de nitrogênio, feita pelo processo Micro Kjeldahl. Esse método é feito em três etapas: digestão, destilação e titulação (INSTITUTO ADOLFO LUTZ, 2008).

Foram pesados 0,2 grama de cada amostra, tanto da in natura como do sna$c k$, em balança analítica; em seguida as amostras foram transferidas para os tubos de digestão, que foram codificados e organizados em uma bandeja, tendo primeiramente o tubo branco, logo a amostra padrão, e os restantes, as outras amostras. Adicionou-se nos tubos 0,3 grama do catalisador $\left(\mathrm{SuSO}_{4} / \mathrm{K}_{2} \mathrm{SO}_{4}\right)$, seguido de 3,5 $\mathrm{ml} \mathrm{de} \mathrm{H}_{2} \mathrm{SO}_{4}$ (ácido sulfúrico concentrado).

Em seguida, os tubos foram colocados em um bloco digestor, com temperatura inicial de $50{ }^{\circ} \mathrm{C}$, com aumento até $350^{\circ} \mathrm{C}$. As amostras ficaram no bloco digestor até mudar a coloração para esverdeado. Após resfriadas, as amostras foram homogeneizadas e adicionou-se $10 \mathrm{ml}$ da água ultrapura e $30 \mathrm{ml}$ de $\mathrm{NaOH} 40 \%$, seguindo-se à destilação e titulação realizada com ácido sulfúrico $0,02 \mathrm{~N}$ e, como indicador o ácido bórico $1 \%$, com mudança de cor de verde para rosado.

O teor de proteína foi calculado com base no volume gasto na titulação, utilizando o fator de conversão $F=6,25$, para transformação do nitrogênio titulado em proteína. Os resultados são expressos em porcentagem e obtidos utilizando a Equação 4. 
Onde:

V: volume de HCL gasto na titulação

$\mathrm{N}$ : normalidade do $\mathrm{H}_{2} \mathrm{SO}_{4}$

F: fator de conversão $(6,25)$

Equação 4 - Expressão matemática para o cálculo do teor de proteína.

\subsubsection{Determinação do teor de carboidratos}

O teor de carboidratos foi calculado por diferença, isto é, as porcentagens de umidade, cinzas, lipídeos e proteínas foram somadas e subtraídas de 100 (INSTITUTO ADOLFO LUTZ, 2008). O teor de carboidrato foi calculado como mostra a Equação 5.

$$
100-(\mathrm{U}+\mathrm{C}+\mathrm{L}+\mathrm{P})
$$

Onde:

U: umidade

C: cinzas

L: lipídeos

P: proteínas

Equação 5 - Expressão matemática para o cálculo do teor de carboidratos

\subsection{Análise estatística}

A determinação da composição proximal foi realizada em triplicata e os resultados são apresentados como médias \pm desvio padrão. A análise de variância (ANOVA) para os resultados de análise sensorial foram realizados com o auxílio do programa Statistica 8.0.

Para elaboração do índice de aceitabilidade (IA), considerou-se as notas médias obtidas no teste de aceitabilidade do produto. O IA (Equação 6) com boa repercussão tem sido considerado superior a 70\% (DUTCOSKY, 1996).

$$
\mathrm{IA}(\%)=\mathrm{A} \times 100 / \mathrm{B}
$$

Onde:

A: nota média obtida para o produto

B: nota máxima dada ao produto

Equação 6 - Expressão matemática para o cálculo do índice de aceitabilidade (IA). 


\section{RESULTADOS E DISCUSSÃO}

A Tabela 10.1 apresenta a intenção de compra para as duas formulações de snack.

Tabela 10.1 Frequência da intenção de compra para cada formulação do snack assado de batata-doce

\begin{tabular}{ccccc}
\hline Intenção & \multicolumn{2}{c}{$\mathbf{F 1}$} & \multicolumn{2}{c}{$\mathbf{F 2}$} \\
\cline { 2 - 5 } de compra & Frequência & \% & Frequência & $\%$ \\
\hline 5 & 1 & 1,25 & 1 & 1,25 \\
4 & 10 & 125,00 & 13 & 19,25 \\
3 & 30 & 37,50 & 22 & 27,54 \\
2 & 24 & 30,00 & 18 & 22,50 \\
1 & 15 & 18,75 & 26 & 32,50 \\
\hline
\end{tabular}

1: Certamente compraria; 2: Provavelmente compraria; 3: Talvez compraria/talvez não compraria;

4: Provavelmente não compraria; 5: Certamente não compraria; F1: formulação de snack com sal rosa;

F2: formulação de snack com chimichurri e sal rosa.

Em relação à intenção de compra (Tabela 10.1), as duas formulações apresentaram resultados diferentes, havendo intenção de compra maior para a formulação 2 .

Na Figura 10.4, mostram-se os resultados de aceitação das amostras de snack.

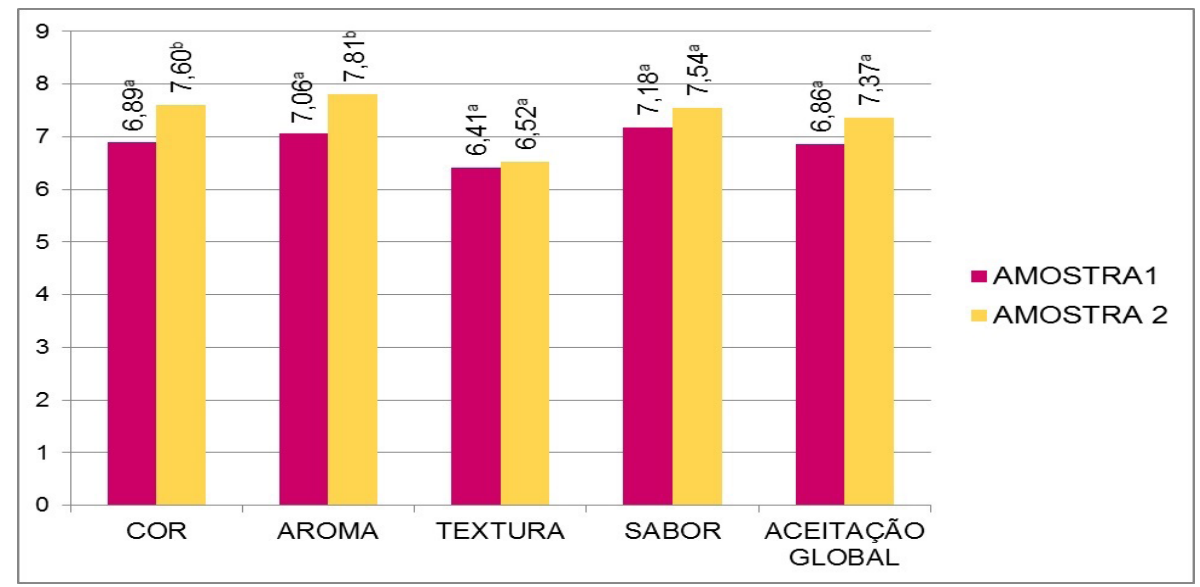

Amostra 1: snack com sal rosa; Amostra 2: snack de chimichurri e sal rosa. Médias acompanhadas de letras diferentes apresentam diferença significativa a $5 \%$.

Figura 10.4 Aceitação das amostras de snack de batata-doce

No teste de aceitação com a escala hedônica de dez pontos, a amostra de sna$c k$ com chimichurri e sal rosa obteve maior aceitação global, com 7,37 de média, 
e o snack com apenas sal rosa teve média 6,86, havendo diferença significativa entre as amostras. Os provadores avaliaram cada amostra de acordo com as características observadas, como cor, aroma, textura e sabor, e essa avaliação foi decisiva para determinar o produto preferido. Dentre os provadores, $56 \%$ eram do sexo masculino, $60 \%$ tinham entre 18 e 20 anos, $40 \%$ consumiam batata-doce semanalmente e $32 \%$ consumiam batata-doce eventualmente. Com um resultado de 7,37 de índice de aceitabilidade, fica provado que o snack teve boa aceitação. Pode-se constatar, segundo a Figura 10.4, que houve diferença significativa entre as amostras 1 (snack com sal rosa) e 2 (snack com chimichurri e sal rosa) em relação à cor, aroma e sabor.

$\mathrm{Na}$ Tabela 10.2, encontram-se os valores da composição proximal da batata-doce in natura e do snack formulado.

Tabela 10.2 Principais componentes da batata-doce in natura e do snack

\begin{tabular}{ccc}
\hline \multirow{2}{*}{ Parâmetro (\%) } & \multicolumn{2}{c}{ Formulação } \\
\cline { 2 - 3 } & $\mathbf{B 1}$ & F2 \\
\hline Umidade & $40,13 \pm 0,04$ & $5,47 \pm 0,00$ \\
Cinzas & $1,62 \pm 0,00$ & $3,40 \pm 0,00$ \\
Proteínas & $0,34 \pm 0,03$ & $1,14 \pm 0,11$ \\
Lipídios & $0,49 \pm 0,23$ & $1,21 \pm 0,68$ \\
Carboidratos & $57,41 \pm 2,30$ & $88,74 \pm 0,64$ \\
\hline
\end{tabular}

Valores são médias \pm desvio padrão dos resultados de triplicatas, em base úmida.

B 1: = batata-doce in natura; F2: = formulação de snack com chimichurri e sal rosa.

Com os resultados da umidade (Tabela 10.2), pode observar-se que a batata in natura possui teor de matéria seca que proporciona bom rendimento industrial, como na formulação dos snacks. A porcentagem de matéria seca, bem como de açúcares, vitaminas e minerais, difere com a variedade dos tubérculos, condições climáticas, tratos culturais, épocas de colheita e duração de armazenamento (EMBRAPA, 1995).

O teor de matéria seca é uma das características determinantes na qualidade dos tubérculos durante a fritura e assamento, como a textura, sabor e o rendimento do chips e do snack (CAPÉZIO et al., 1993).

Os teores de cinzas (Tabela 10.2) apresentaram valores de 3,40\% para a amostra de snack, e 1,62\% para a amostra da batata-doce in natura, demonstrando um menor valor de cinzas para a segunda amostra, pois o snack possui adição de tempero e menos água, assim, tem mais minerais. Ambos os resultados 
estão em concordância com Leonel, Jackey e Cereda (1998), conforme o Quadro 10.1. No snack desenvolvido neste trabalho, os constituintes, como as especiarias e o sal rosa, possuem características antioxidantes, desintoxicantes e, por ter poucas calorias e muitos nutrientes, fornece energia e faz com que haja queima de calorias.

O teor de proteína da batata-doce in natura encontra-se maior do que para o snack, mas ambos apresentaram diferença significativa em relação aos valores encontrados por Leonel, Jackey e Cereda (1998) (Quadro 10.1), cujos resultados apresentaram maior teor de proteína. Mesmo o teor de proteína sendo menor nos snacks, este ainda se torna eficiente para o ganho de massa, pois pessoas fisicamente ativas necessitam de uma dieta balanceada em nutrientes como carboidratos, proteínas, vitaminas, gorduras e minerais.

Obteve-se valor maior de lipídeos para as amostras de snack em comparação à amostra de batata-doce in natura (Tabela 10.2) devido ao processo de desidratação. Os valores de lipídios para as amostras in natura estão de acordo com os resultados de Leonel, Jackey e Cereda (1998) (Quadro 10.1). Comparado com uma batata chips disponível no mercado, que contém 36\% de lipídios (ELMA CHIPS, 2014), o teor de lipídios do snack é bastante interessante do ponto de vista de saúde, pois apresenta valores mínimos desse nutriente. Além disso, esse é um produto inovador, pois os produtos existentes com baixo teor de lipídios e pouco sódio têm partição mínima no mercado.

Os valores de carboidratos são semelhantes aos de Leonel, Jackey e Cereda (1998) (Quadro 10.1). Além de possuírem grande quantidade de carboidratos, os snacks apresentam baixo conteúdo de água, auxiliando na textura crocante do produto e na sua conservação, resultando em maior durabilidade. O teor de carboidratos ajuda o cérebro a produzir glicose, fornecendo mais energia, evitando a letargia que acompanha regimes de perda de peso e, por isso, o snack seria uma alternativa saudável de um alimento à base de batata-doce.

\begin{tabular}{cccccccccccc}
\hline \multirow{2}{*}{ Variáveis } & \multicolumn{3}{c}{ Raízes } & \multicolumn{4}{c}{ Fécula } & \multicolumn{3}{c}{ Bagaço } \\
\cline { 2 - 9 } & $\begin{array}{c}\text { média } \\
\mathbf{g} / 100 \mathrm{~g}\end{array}$ & $\begin{array}{c}\text { Desvio } \\
\text { padrão }\end{array}$ & CV \% & média & $\begin{array}{c}\text { Desvio } \\
\text { padrão }\end{array}$ & CV \% & Média & $\begin{array}{c}\text { Desvio } \\
\text { padrão }\end{array}$ & CV \% \\
\hline $\begin{array}{c}\text { Umidade Inicial } \\
\text { Carboidratos } \\
\text { totais }\end{array}$ & 62,86 & 0,452 & 0,72 & 13,75 & 0,070 & 0,51 & 16,19 & 1,453 & 8,97 \\
$\begin{array}{c}\text { Açucares } \\
\text { solúveis }\end{array}$ & 13,92 & 0,692 & 4,97 & 1,31 & 0,151 & 11,55 & 1,55 & 0,218 & 14,06 \\
Amido & 76,37 & 1,384 & 1,81 & 96,66 & 0,420 & 0,43 & 79,94 & 0,893 & 1,17 \\
\hline
\end{tabular}




\begin{tabular}{cccccccccccc}
\hline \multirow{2}{*}{ Variáveis } & \multicolumn{4}{c}{ Raízes } & \multicolumn{4}{c}{ Fécula } & \multicolumn{3}{c}{ Bagaç̦o } \\
\cline { 2 - 10 } & $\begin{array}{c}\text { média } \\
\mathbf{g} / 100 \mathbf{g}\end{array}$ & $\begin{array}{c}\text { Desvio } \\
\text { padrão }\end{array}$ & CV \% & média & $\begin{array}{c}\text { Desvio } \\
\text { padrão }\end{array}$ & CV \% & Média & $\begin{array}{c}\text { Desvio } \\
\text { padrão }\end{array}$ & CV \% \\
\hline Fibras & 3,44 & 0,199 & 5,79 & 0,57 & 0,010 & 1,75 & 11,13 & 1,111 & 9,98 \\
Cinzas & 3,42 & 0,160 & 4,68 & 0,50 & 0,153 & 3,03 & 3,23 & 0,617 & 19,11 \\
Proteínas & 4,55 & 0,075 & 1,66 & 0,05 & 0,002 & 4,00 & 2,29 & 0,344 & 15,02 \\
Matéria graxa & 0,16 & 0,010 & 6,25 & 0,005 & 0,0005 & 8,82 & 0,53 & 0,010 & 1,89 \\
pH & 5,6 & 0,100 & 1,79 & 6,37 & 0,035 & 0,55 & 5,58 & 0,123 & 2,20 \\
Acidez * & 9,0 & 0,050 & 0,56 & 0,93 & 0,115 & 12,37 & 3,15 & 0,575 & 18,22 \\
\hline
\end{tabular}

Fonte: Leonel, Jackey e Cereda (1998)

Quadro 10.1 Valores médios das análises físico-químicas das raízes, fécula e bagaço da batata-doce

Tabela 10.3 Comparação das informações nutricionais da batata-doce

\begin{tabular}{ccccc}
\hline Produto & $\begin{array}{c}\text { Calorias } \\
(\mathbf{k c a l} / \mathbf{g})\end{array}$ & $\begin{array}{c}\text { Carboidratos } \\
(\mathbf{g})\end{array}$ & $\begin{array}{c}\text { Proteínas } \\
(\mathbf{g})\end{array}$ & $\begin{array}{c}\text { Lipídeos } \\
\mathbf{( g )}\end{array}$ \\
\hline $\begin{array}{c}\text { Batata-doce roxa in natura } \\
\text { Batata-doce roxa } \\
\text { desidratada }\end{array}$ & 94,9 & 21,70 & 1,82 & 0,10 \\
$\begin{array}{c}\text { Snack de batata-doce roxa } \\
\text { (370,0 }\end{array}$ & 84,50 & 5,00 & 1,0 \\
\hline
\end{tabular}

Fonte: FRANCO, 1996.

A batata-doce é um alimento ideal para as pessoas que praticam atividade física por seu alto teor de carboidratos e baixo índice glicêmico, fornecendo energia ao organismo. Assim, o snack seria um alimento à base dessa matéria-prima, focado principalmente nos consumidores que preferem uma refeição rápida e saudável, com um bom valor nutricional quando comparada ao seu produto de origem. Pode-se observar, por meio das coletas de dados, que os valores encontrados nas análises físico-químicas estão de acordo com algumas literaturas estudadas (Tabela 10.3), tanto para as amostras in natura quanto para os snacks. Assim, os snacks se enquadram na categoria de alimentos práticos e saudáveis, proporcionando uma dieta com aumento da massa muscular, rica em nutrientes, o sal rosa adicionado, que é antioxidante e evita a retenção de água, enquanto o índice glicêmico baixo irá estabilizar os níveis de açúcar no sangue, mantendo o organismo mais saudável. 


\section{CONCLUSÃO}

Conclui-se que o snack assado de batata-doce produzido neste trabalho seria um alimento inovador no mercado, com baixo teor de gordura. Além disso, por conter níveis baixos de umidade, é um produto de vida útil longa e armazenável em temperatura ambiente, com pouca adição de sódio. O produto desenvolvido neste trabalho pode trazer um benefício a mais para os praticantes de musculação e para pessoas com bom condicionamento físico, evitando a retenção de água. Assim, esse produto, além de ser comercializado em mercados, poderia também ser vendido em academias.

\section{REFERÊNCIAS}

ABREU, E. S.; VIANA, I. C.; MORENO, R. B.; TORRES, E. A. F. S. Alimentação mundial - uma reflexão sobre a história. Saúde e Sociedade, v. 10, n. 2, p. 3-14, 2001. ADITIVOS E INGREDIENTES. O sal e seus substitutos. Disponível em: <www. insumos.com.br/aditivos_e_ingredientes/materias/246.pdf>. Acesso em: 10 jun. 2014. ALMEIDA, A. P. G. Avaliação da influência do processo de irradiação em especiarias utilizando a técnica de difração de raio x. 2006. 94f. Dissertação (Mestrado em Engenharia Nuclear) - Universidade Federal do Rio de Janeiro, Rio de Janeiro, 2006. ALIMENTOS E BEBIDAS. Snacks passo a passo na fabricação. Disponível em: <http:// revistaalimentosebebidas.blogspot.com.br/2012/08/snackspasso-passo-na-fabricacaodos.html>. Acesso em: 23 jun. 2014.

ALTON, W. J. Microwave pasteurization of liquids. Society of Manufacturing Engineers Paper, Dearborn, n. eM98-211, 1998.

BRASIL. Ministério da Saúde. Secretaria de Atenção à Saúde. Departamento de Atenção Básica. Guia Alimentar para a População Brasileira: promovendo a alimentação saudável. Brasília, DF: Ministério da Saúde, 2008.

. Ministério da Saúde. Resolução RDC n 360, de 23 de novembro de 2003.

Regulamento Técnico sobre Rotulagem Nutricional de Alimentos Embalados. Diário Oficial da União, Brasília, DF, 26 dez. 2003.

BEDIN, C.; GUTKOSKI, S. B.; WIEST, J. M. Atividade antimicrobiana das especiarias. Higiene Alimentar, v. 13, n. 65, p. 26-29, 1999.

BEZERRA, I. N.; SICHIERI, R. Características e gastos com alimentação fora do domicílio no Brasil. Revi Saúde Pública. São Paulo, v. 44, n. 2, abr. 2010.

BOUWKAMP, J. C. Sweet potato products: a natural resource for the tropics. Florida: CRC Press, 1985.

CALEFFI, R. Portal Orgânico: sal rosa himalaia. 2012. Disponível em: <http://www. portalorganico.com.br/artigo/49/sal_do_himalaia_voce_conhece>. Acesso em: 5 mai. 2014. CAPÉZIO, S.; HUARTE, M.; CARROZZI, L. Selección por peso especifico en generaciones tempranas en el mejoramiento de la papa. Revista Latinoamericana de la Papa, v. 6, p. 54-63, 1993. 
CARVALHO, T. Modificações dietéticas, reposição hídrica, suplementos alimentares e drogas: comprovação de ação ergue gênicos e potenciais riscos para a saúde. Revista Brasileira de Medicina do Esporte, Niterói, v. 9, n. 2, p. 43-56, mar./abr. 2003. CEREDA, M. P.; VILPOUX. O. F.; FRANCO, C. M. L. Uso de amido e seus derivados na produção de salgadinhos extrusados (snacks). In: CEREDA, M. P.; VILPOUX, O. F. (Org.). Tecnologia, usos e potencialidades de tuberosas amiláceas Latino Americanas. v. 3. São Paulo: Fundação Cargill, 2003. p. 132-142.

COELHO, C. F.; SAKZENIAN, V. M.; BURINI, R. C. Ingestão de carboidratos e desempenho físico. Revista Nutrição em Pauta, v. 4., n. 67. p. 51- 56, 2004.

COSTA, P. F. P. et al. Functional extruded snacks with lycopene and soy protein. Ciência e Tecnologia de Alimentos, v. 30, n. 1, p. 143-151, 2010.

COYLE, E. F. Altos e baixos das dietas à base de carboidratos. Sports Science Exchange, São Paulo, n. 42, p. 1-6, jan.-mar. 2005.

CYRINO, E. S.; ZUCAS, S. M. Influência da ingestão de carboidratos sobre o desempenho físico. Revista da Educação Física, Maringá, v. 10, n. 1, p. 73-79, 1999. DUTCOSKY, S. D. Análise sensorial de alimentos. Curitiba: Champagnat, 1996. ELMA CHIPS. Sensações. Disponível em: <http://www.pepsico.com.br/sensacoes>. Acesso em: 10 jun. 2014.

EMBRAPA - Empresa Brasileira de Pesquisa Agropecuária. Sistema de produção de batata-doce. 2007. Disponível em: <http://sistemasdeproducao.cnptia.embrapa.br/ FontesHTML/Batata- doce/SistemaProducaoBatata-doce/caracteristicas.htm>. Acesso em: 3 ago. 2013.

. Centro Nacional de Pesquisas de Hortaliças (EMBRAPA - CNPH). Instruções técnicas 7. Cultivo da batata-doce (Ipomoea batata). 3. ed. Brasília, DF: Ministério da Agricultura, Abastecimento e Reforma Agrária, 1995.

FONTES, L. C. B. et al. Efeito das condições operacionais no processo de desidratação osmótica de batata-doce. Revista Brasileira de Produtos Agroindustriais, Campina Grande, v. 14, n. 1, p. 1-13, 2012.

FRANCO, G. Tabela de Composição Química dos Alimentos. 9. ed. São Paulo: Atheneu, 1996. 307 p.

G1. Agronegócios. Produtores de batata-doce do sul de MG comemoram o bom preço. 2013. Disponível em: <http://g1.globo.com/economia/agronegocios/noticia/2013/08/ produtores-de-batata-doce-do-sul-de-mg-comemoram-o-bom-preco.html>. Acesso em: 03 ago. 2013.

GERMANO, P. M. L.; GERMANO, M. I. S. Importância e riscos das especiarias. Higiene Alimentar, v. 12, n. 57, p. 23-31, 1998.

GOMES, H. Snacks de frutas devem crescer 35\%. 2009. Disponivel em: <http://www. sm.com.br/Editorias/Categorias/Snacks-de-frutas-devem-crescer-35\%25-3555.html> Acesso em: 12 jun, 2014.

GOULD, G. W. Industry perspective on the use of natural antimicrobials and inhibitors for food applications. J. Food Protection, v. 58, n. 1, p. 82-86, 1995. 
GUERRA, I. Importância da alimentação do atleta visando a melhora da performance. Revista Nutrição em Pauta. v. 4, p. 63-66, 2002.

INMETRO: Forno de micro-ondas. 2000. Disponível em: <http://www.inmetro.gov.br/ consumidor/produtos/microondas.asp >. Acesso em: 2 abr. 2014.

INSTITUTO ADOLFO LUTZ (São Paulo). Procedimentos e determinações gerais. In:__. Métodos físico-químicos para análise de alimentos. 1. ed. digital. São Paulo: Instituto Adolfo Lutz, 2008. p. 83-158.

KRUGER, M. F. Controle de Listeria monocytogenes em linguiça frescal refrigerada através do uso de óleo essencial de orégano e nisina. 2006. 74f. Dissertação (Mestrado em Ciência dos Alimentos) - Faculdade de Ciências Farmacêuticas, Universidade de São Paulo, São Paulo, 2006.

LANE, D. The Salt Enthusiasts Scrapbook. Raleigh: Lulu.com, 2008. 232 p.

LEONEL, M.; JACKEY, S.; CEREDA, M. P. Processamento industrial de fécula de mandioca e batata-doce - um estudo de caso. Cienc. Tecnol. Aliment., v. 18, n. 3, p. 343-345, 1998.

LEONEL, M.; CEREDA, M. P. Caracterização físico-química de algumas tuberosas amiláceas. Cienc. Tecnol. Aliment., v. 22, n. 1, p. 65-69, 2002.

LIMBERGER, M. V. Modificação física e química do amido de quirera de arroz para aproveitamento na indústria de alimentos. 2006. Dissertação (Mestrado em Ciência e Tecnologia de Alimentos) - Universidade Federal de Santa Maria, Santa Maria, 2006.

MAUGHAN, R. et al,. Bioquímica do exercício e do treinamento. Tradução de Elisabeth de Oliveira. São Paulo: Manole, 2000.

MERMELSTEIN, N. H. How food technology covered microwaves over the years.

Food Technology, v. 51, n. 5, p. 82-84, 1997.

PERES, Rodolfo. Viva em dieta viva melhor. 1. ed. São Paulo: Phorte, 2012.

PEREIRA, M. C. et al. Inibição do desenvolvimento fúngico através da utilização de óleos essenciais de condimentos. Ciências Agrotécnicas, v. 30, n. 4, p. 731-738, 2006. POMIN; V. H.; MOURÃO, P. A. de S. Carboidratos. Ciência Hoje, v. 39, n. 233, p. 2431. 2006.

PRESEA ALIMENTOS. Frutas desidratas. Disponível em: <www.presea.com.br $>$ Acesso em: 22 jun. 2014.

ROGÉRIO, W. F; LEONEL, M. Efeitos da espessura das fatias e pré-cozimento na qualidade de salgadinhos fritos (chips) de tuberosas tropicais. Alim. Nutr., Araraquara, v. 15, n. 2, p. 131-137, 2004.

ROSINI, F; NASCENTES, C. C; NÓBREGA, J. A. Experimento didático envolvendo radiação micro-ondas. Quim. Nova, v. 27, n. 6, p. 1012-1015, 2004.

SAPATA, K. B; FAYH, A. P. F; OLIVEIRA, Á. Efeitos do consumo prévio de carboidratos sobre a resposta glicêmica e desempenho. Rev. Bras. Med. Esporte, v. 12, n. 4, 2006.

SOUZA, A. B; SANDRI, T. Avaliação preliminar de introduções de batata-doce e parâmetros agronômicos e a aspectos comerciais e culinários. Semina, v. 11, n. 1, p. 12-15, 1990. 
TRONCOSO, L.; GUIJA, E.; QUIROZ, K. Capacidad antioxidante del chimichurri y sus componentes. In: Libro de resúmenes. Segundo Congreso Internacional FITO 2003 y do Congreso Peruano de Plantas Medicinales y Fitoterapia. Lima, Perú: Instituto de Fitoterapia Americano; 2003.

VILlanUeVA, N. D. M.; PETENATE, A. J.; SILVA, M. A. A. P. Performance of the hybrid hedonic scale as compared to the traditional hedonic, self-adjusting and ranking scales. Food Quality and Preference, v. 16, p. 691-703, 2005.

ZELAYA, M. P. O papel da adesão e de amidos resistentes em snacks e cereais. Food Ingredients, São Paulo, v. 11, n. 9, 2000. 